\title{
Perfil epidemiológico do surto de doença meningocócica na regional de saúde de Balsas-MA, 2012
}

\author{
Epidemiological profile of meningococcal disease outbreak in regional health Balsas- \\ MA, 2012
}

\author{
Paulo Luis Ribeiro Aguiar Filho ${ }^{1}$ Silvio Gomes Monteiro ${ }^{2}$
}

\begin{abstract}
Resumo: Introdução: A doença meningocócica (DM) é um sério problema de saúde pública em várias localidades do mundo. Estima-se que no mundo aproximadamente 500.000 casos de doença meningocócica invasiva ocorrem todo ano, deixando cerca de 60.000 pacientes com sequelas permanentes, resultando em mais de 50.000 mortes. A meningite pode ser causada por diversos agentes infecciosos, como bactérias, vírus e fungos e por agentes não-infecciosos (ex: traumatismo). As meningites de origem infecciosa, principalmente as causadas por bactérias e vírus, são as mais importantes do ponto de vista da saúde pública, pela magnitude de sua ocorrência e potencial de produzir surtos. Objetivo: Confirmar a existência do surto de doença meningocócica na regional de saúde de Balsas. Material e Métodos: Foi realizado estudo retrospectivo de base populacional na regional de saúde de Balsas onde foram avaliados todos os pacientes identificados com doença meningocócica de Janeiro a Dezembro de 2012. Para análise estatística utilizou-se o programa IBM SPSS Statistics 20. Resultados: dos 46 casos investigados, $72 \%$ foram confirmados, $24 \%$ foram descartados, e 4\% em investigação. Quanto à distribuição destes, conforme o município de residência, verificou-se que 58\% eram oriundos de Sambaíba, 15\% de Loreto, $12 \%$ de São Raimundo das Mangabeiras, $6 \%$ de Balsas, e 3\% de Riachão, São Félix de Balsas e Fortaleza dos Nogueiras, respectivamente. De acordo com a investigação, 33 casos foram confirmados, dos quais $21 \%$ foram a óbito. O sexo masculino se caracterizou por apresentar os maiores coeficientes de incidência, $64 \%$. Conclusão: Ocorreu um surto de Doença Meningocócica no ano de 2012 na regional de saúde de Balsas/MA.
\end{abstract}

Palavras-chave: Doença meningocócica. Saúde pública. Balsas-MA.

Abstract:: Introduction: Meningococcal disease (MD) is a serious public health problem in several locations worldwide. In the world it is estimated that approximately 500,000 cases of invasive meningococcal disease occur every year, leaving around 60,000 patients with permanent sequelae resulting in over 50,000 deaths. Meningitis can be caused by various infectious agents like bacteria, viruses and fungi, among others, and non-infectious agents (eg, trauma). Meningitis of infectious origin, especially those caused by bacteria and viruses are the most important from a public health point of view due the magnitude of its occurrence and potential to produce outbreaks. Objective: To confirm the existence of meningococcal disease outbreak in Balsas health regional. Methods: We conducted a retrospective population-based study in Balsas health of regional where we evaluated all patients identified with meningococcal disease from January to December 2012. The statistical analysis used the IBM SPSS Statistics program 20. Results: of the 46 cases investigated, $72 \%$ were confirmed, $24 \%$ were discarded, and $4 \%$ in research. As for the distribution of these as the municipality of residence, it was found that $58 \%$ were from Sambaíba, $15 \%$ of Loreto, $12 \%$ of São Raimundo das Mangabeiras, 6\% of Balsas, and 3\% Riachão, São Félix de Balsas and strength of Walnut, respectively. According to the research 33 cases have been confirmed of which $21 \%$ died. The male was characterized by the highest incidence rates $64 \%$. Conclusion: There was an outbreak of Meningococcal Disease in health regional Balsas / Ma in 2012.

Keywords: Meningococcal disease. Public health. Balsas/MA.

1 - Graduado do Curso de Medicina - UNICEUMA

2 - Docente Permanente do Programa de Mestrado em Biologia Parasitária da Universidade CEUMA, Maranhão. 


\section{Introdução}

A Doença Meningocócica (DM) é um sério problema de saúde pública em várias localidades do mundo. Estima-se que aproximadamente 500.000 casos de doença meningocócica invasiva ocorrem todo ano, deixando cerca de 60.000 pacientes com sequelas permanentes resultando em mais de 50.000 mortes no mundo. ${ }^{1}$

É muito conhecida a área endêmica da Etiópia à Mauritânia, denominada como "Cinturão Africano", onde a média de casos registrada é de até 20 casos a cada 100 mil habitantes por ano. ${ }^{2}$

No Brasil a DM é considerada uma doença endêmica, já que sua ocorrência é esperada ao longo de todo 0 ano, sendo frequente a ocorrência de surtos comunitários ou institucionais. ${ }^{3}$ No ano de 2011 foram notificados 20.762 casos no Sistema de Informação de Agravos de Notificação. ${ }^{4}$

Define-se um surto, no Brasil, quando há a ocorrência de três ou mais casos, confirmados ou prováveis, em um período de 3 meses, que residam na mesma área geográfica, gerando uma taxa de ataque maior ou igual a 10 casos em 100.000 habitantes. ${ }^{5}$

A meningite pode ser causada por diversos agentes infecciosos, como bactérias, vírus e fungos, dentre outros, e agentes não-infecciosos (ex: traumatismo). As meningites de origem infecciosa, principalmente as causadas por bactérias e vírus, são as mais importantes do ponto de vista da saúde pública, pela magnitude de sua ocorrência e potencial de produzir surtos. $^{6}$

O principal agente etiológico da doença meningocócica capaz de causar epidemias, a Neisseria meningitidis, é um diplococo gram- negativo, aeróbio, imóvel, pertencente à família Neisseriaceae. A composição antigênica da cápsula polissacarídica permite a classificação do meningococo em 13 diferentes sorogrupos: A, B, C, D, H, I, K, L, W135, X, Y, Z e 29E. Atualmente, os sorogrupos $A, B, C, Y, W 135$ e $X$ são responsáveis por virtualmente todos os casos de doença infectando apenas humanos. ${ }^{7}$

A infecção invasiva pela Neisseria meningitidis resulta em amplo espectro clínico de doença, que inclui a meningite $e$ a meningococemia, ou ambas, sendo a meningite a forma clínica mais frequentemente observada. A denominação doença meningocócica torna-se apropriada nesse contexto, sendo adotada internacionalmente. ${ }^{5}$

A DM é a principal causa de meningite bacteriana, sendo 0 sorogrupo $\mathrm{C}$ o de maior prevalência na maioria das regiões do país e o responsável pela maioria dos surtos notificados desde 2006 . $^{3}$

Em geral, a transmissão é de pessoa a pessoa, através das vias respiratórias, por gotículas e secreções da nasofaringe, havendo necessidade de contato íntimo ou contato direto com as secreções respiratórias do paciente. O período de incubação em geral é de 2 a 10 dias, em média 3 a 4 dias. ${ }^{5}$

A doença tem início súbito, os sinais e sintomas mais comuns são febre alta, cefaleia, vômito, rigidez de nuca, náusea, prostração, confusão mental, e sinais de irritação meníngea (Sinal de Kernig e Sinal de Brudzinsky). ${ }^{8}$

O diagnóstico pode ser realizado através do exame clínico, acompanhado de exame laboratorial do líquido cefalorraquidiano (LCR), pelos métodos de cultura da espécie presentes no LCR, testes de aglutinação (Látex), ou reação em 
cadeia pela polimerase (PCR), método que permite a identificação do sorogrupo, o qual é importante para definir medidas de controle. ${ }^{9}$

Até mesmo quando a doença é diagnosticada rapidamente e 0 tratamento adequado é iniciado, 5 a $10 \%$ dos pacientes evoluem a óbito, geralmente 24 a 48 horas após 0 aparecimento dos sintomas. ${ }^{9}$

O Sistema de Informação de Agravos de Notificação (SINAN) tem como objetivo recolher dados de notificação e processo para doenças e agravos que constam da lista nacional de doenças de notificação compulsória no Brasil, e permite que estados e municípios incluam outros problemas importantes de saúde de sua região na lista. ${ }^{10}$

O Sistema de Vigilância Epidemiológica para Meningite, implementado em 1975 com o objetivo inicial de controle de surtos da DM no país, compreende todas as atividades e os agentes envolvidos no processo, desde a identificação de um caso suspeito para a adoção de medidas de prevenção até o controle da doença na comunidade. $\mathrm{O}$ funcionamento do sistema pressupõe uma boa integração técnica entre a assistência prestada aos pacientes, a identificação e estudo das características do agente etiológico, e análise epidemiológica do comportamento da doença na população. ${ }^{11}$.

A fim de ampliar o conhecimento sobre a dinâmica do surto da DM no Estado do Maranhão, foi realizado um estudo retrospectivo para descrever o perfil epidemiológico do surto da doença de acordo com sua faixa etária e sexo, na Regional de Saúde de Balsas no ano de 2012.

\section{Métodos}

Trata-se de um estudo retrospectivo, de base populacional que incidiu sobre a epidemiologia do surto de doença meningocócica ocorrido no Estado do Maranhão na mesorregião sul, composta por 14 municípios pertencentes à Regional de Saúde de Balsas (Balsas, São Raimundo das Mangabeiras, Loreto, São Felix de Balsas, Sambaíba, Alto Parnaíba, Carolina, Feira Nova do Maranhão, Fortaleza dos Nogueiras, Formosa da Serra Negra, Riachão, Nova Colinas, São Pedro dos Crentes e Tasso Fragoso). O período de estudo foi de 12 meses, entre janeiro e dezembro de 2012.

O banco de dados eletrônico para as notificações confirmadas de doença meningocócica foi desenvolvido a partir do SINAN fornecido pela Secretaria de Saúde do Estado do Maranhão (SES/MA). O perfil epidemiológico do surto da doença meningocócica foi descrito de acordo com as variáveis dos arquivos individuais de investigação. As informações estão dispostas de acordo com: a idade, sexo, área de residência, zona de moradia, atividade laboral, hábito de compartilhar talheres, estado civil, número de óbitos, sinais e sintomas, classificação do caso e os critérios de confirmação.

Os dados populacionais para os grupos etários necessários para o cálculo dos coeficientes foram fornecidos pelo Instituto Brasileiro de Geografia e Estatística. ${ }^{12}$

As variáveis utilizadas para definir a população foram: população, ano de referência, local de residência, faixa etária e gênero. Onze grupos de idade serão considerados ( $<1$ ano, 1-2 anos, 3-4 anos, 5-9 anos, 10-14 anos, 15-19 anos, 20-29 anos, 30-39 anos, 40-49 anos, 50-59 anos, 60-69 anos) para o cálculo da taxa de incidência, mortalidade, e letalidade.

Para delimitação da população a ser investigada, utilizou-se as seguintes definições: 
Caso suspeito: indivíduo residente na Regional de Saúde de Balsas/MA, que no período de Janeiro a Dezembro de 2012 foi atendido nas unidades de saúde da regional de Balsas, e classificado como suspeito para meningite pela Equipe Médica ou indivíduo, que apresentou febre acompanhada de pelo menos um dos seguintes sintomas: cefaleia, vômito, rigidez de nuca, petéquias, manchas avermelhadas ou dor abdominal.

Caso confirmado: caso suspeito que apresentou confirmação laboratorial por exames específicos (cultura, látex ou reação de cadeia pela polimerase), e/ou exame laboratorial inespecífico (bacterioscopia positiva-diplococo gram negativo) ou vínculo epidemiológico com caso confirmado laboratorialmente por cultura, látex ou PCR, ou febre acompanhado de cefaleia ou vômito, e/ou rigidez de nuca, petéquias, manchas avermelhadas ou dor abdominal.

Caso descartado: Caso suspeito que não apresentou clínica sugestiva, vínculo epidemiológico ou exames negativos sem clínica sugestiva.

Os dados foram avaliados pelo programa IBM SPSS Statistics 20, versão 2011. Inicialmente, foram feitas as análises da estatística descritiva, ou seja, através de gráficos e tabelas de frequência das variáveis analisadas, estimativa de média, desvio-padrão, máximo e mínimo das variáveis numéricas.

Posteriormente, para se fazer a associação das variáveis classificatórias foi feito teste não paramétrico de Qui-quadrado de independência $\left(\chi^{2}\right)$. O nível de significância para se rejeitar a hipótese de nulidade será de $5 \%$, ou seja, considerar-se-á como estatisticamente significante um valor de $p<0,05$.

Embora 0 banco de dados fornecido pela SES/MA não possua variáveis que identifiquem os pacientes, o estudo foi submetido e aprovado no Comitê de Ética em Pesquisa da Universidade CEUMA, sob o parecer consubstanciado 769184.

\section{Resultados e discussão}

\section{Local de estudo}

A investigação dos casos foi realizada nos municípios de Balsas, São Raimundo das Mangabeiras, Loreto, São Felix de Balsas, Sambaíba e Feira Nova do Maranhão, estes apresentaram casos suspeitos, conforme descrito na tabela 1.

As figuras 1 e 2 mostram a localização geográfica da região e áreas pesquisadas

Tabela 1 - Descrição dos municípios incluídos na investigação. Regional de Saúde de Balsas/MA, 2012 12,21

\begin{tabular}{|c|c|c|c|c|}
\hline Município & $\begin{array}{ll}\text { Área } \\
(\mathrm{Km} 2)\end{array}$ & População & IDH & $\begin{array}{l}\text { № de unidades } \\
\text { de saúde }\end{array}$ \\
\hline Balsas & $13.141,69$ & 83.459 & 0,696 & 95 \\
\hline S R Mangabeiras & $3.521,51$ & 17.480 & 0,638 & 10 \\
\hline Loreto & $3.596,83$ & 11.495 & 0,603 & 6 \\
\hline Sambaíba & $2.478,69$ & 5.487 & 0,609 & 4 \\
\hline S F das Balsas & $2.032,30$ & 4.688 & 0,595 & 5 \\
\hline $\begin{array}{l}\text { Fort } \\
\text { Nogueiras }\end{array}$ & $1.664,06$ & 11.644 & 0,637 & 6 \\
\hline
\end{tabular}


Figura 1 - Localização do Estado do Maranhão e municípios envolvidos no surto de meningite na região de Balsas, $2012^{*}$
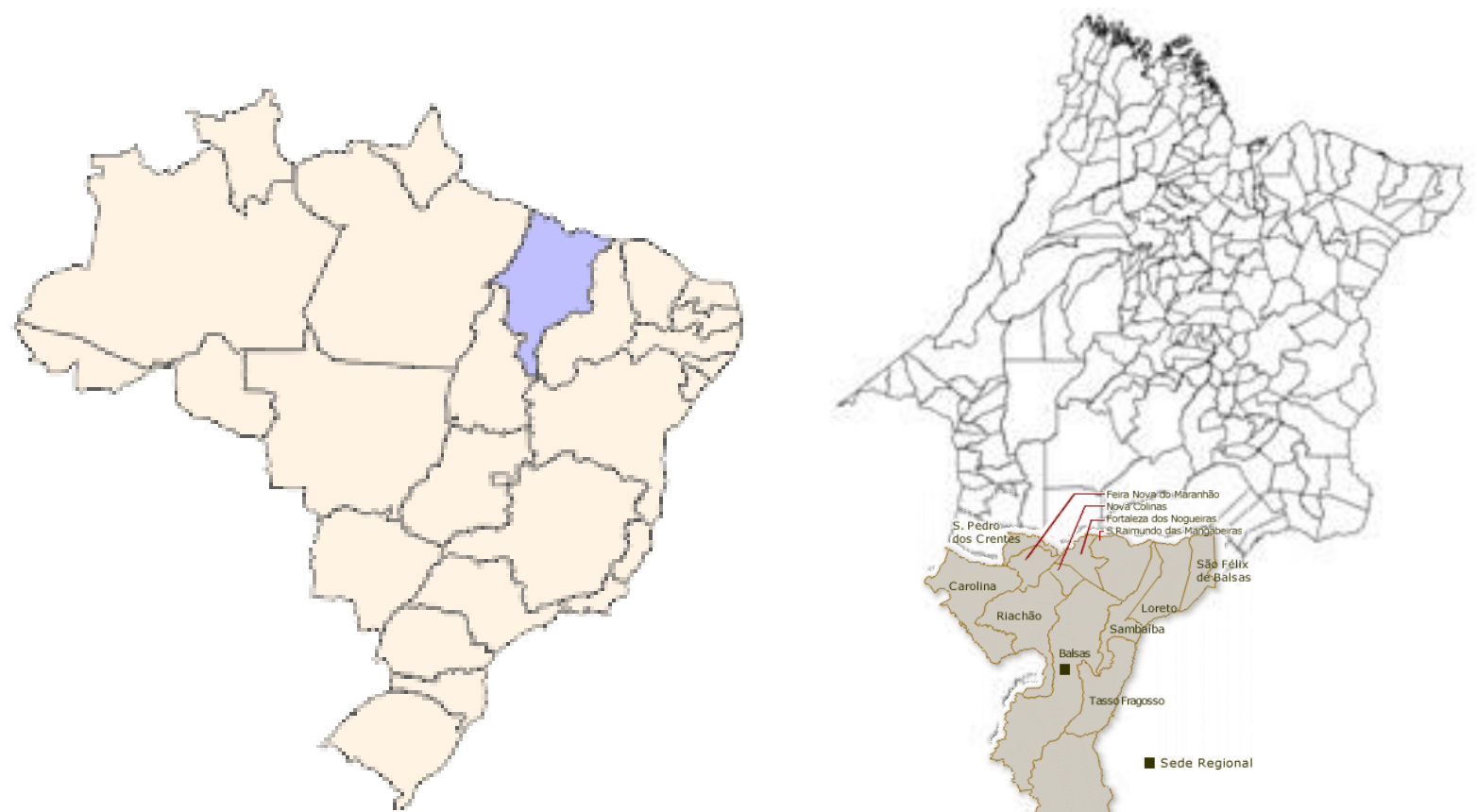

*Dados fornecidos pela Regional de Saúde de Balsas/MA

Figura 2 - Localização da Regional de Balsas - Estado do Maranhão*
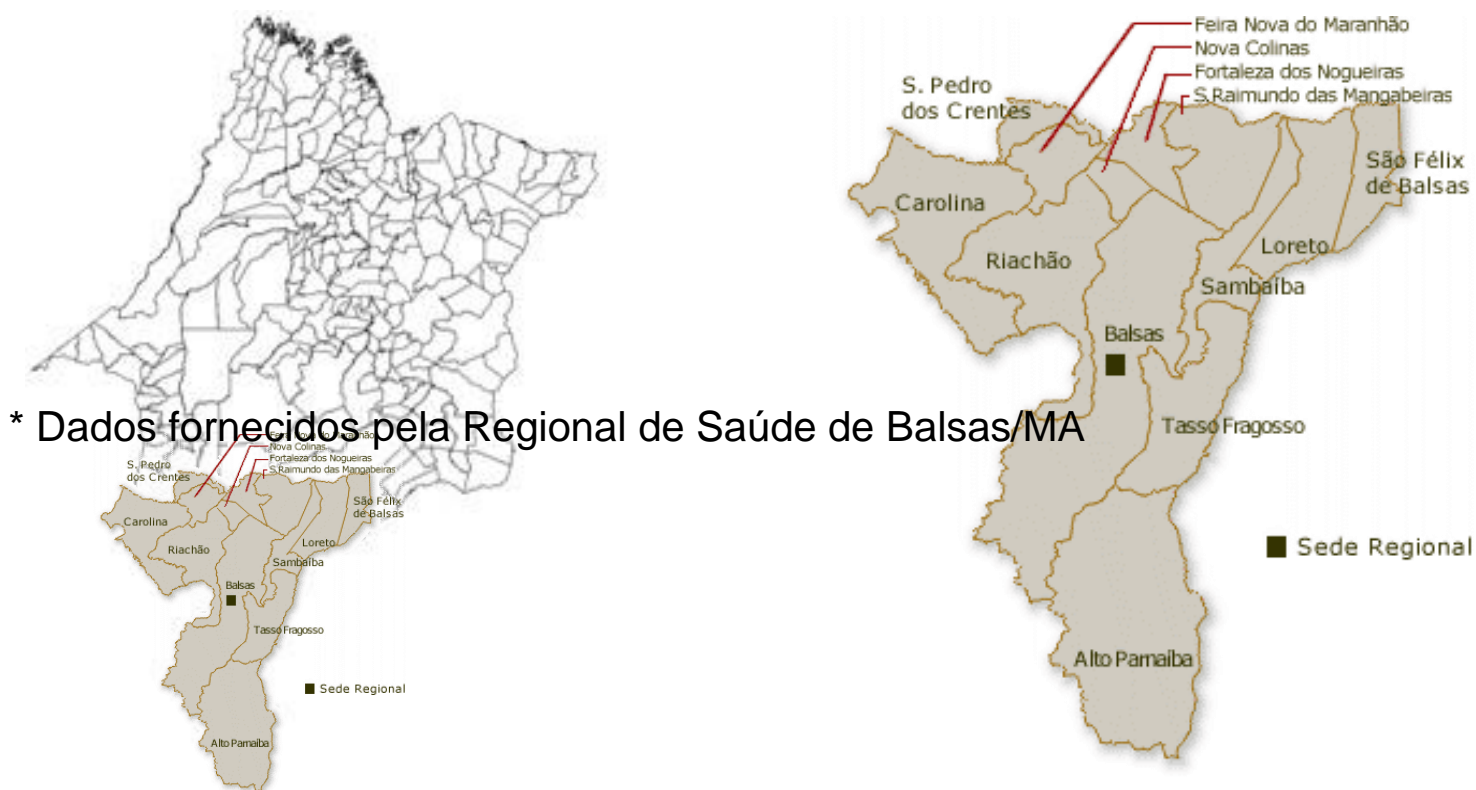


\section{Série histórica}

Em análise da série histórica dos anos de 2009 a 2012, dos casos de doença meningocócica nos municípios que pertencem à Regional de Balsas, detectou-se uma média de 5 casos por ano, e em 2012 houve um incremento de 28 casos, o que caracteriza um surto,conforme ilustrado no gráfico 1.

\section{Descrição de casos}

Dos 46 casos investigados, $72 \%$ foram confirmados, $24 \%$ foram descartados, e 4\% em investigação. Quanto à distribuição destes, conforme os municípios de residência, verificouse que $58 \%$ eram oriundos de Sambaíba, $15 \%$ de Loreto, $12 \%$ de São Raimundo das Mangabeiras, 6\% de Balsas, e 3\% de Riachão, São Félix de Balsas e Fortaleza dos Nogueiras, respectivamente, conforme a tabela 2 .

De acordo com a investigação, 33 casos foram confirmados, dos quais $21 \%$ foram a óbito. O sexo masculino se caracterizou por apresentar os maiores coeficientes de incidência (64\%). Esse achado é equivalente ao encontrado por Gama et al. ${ }^{13}$, em seu estudo sobre o agravo na cidade do Rio de Janeiro, também descrito por outros autores. ${ }^{14,15}$

Quanto ao estado civil, 73\% eram solteiros, $24 \%$ eram casados e $3 \%$ viúvos (Tabela 3 ).

Os casos de óbitos confirmados estão concentrados na faixa etária de 5 a 39 anos. Tal fato discorda com vários pesquisadores ${ }^{16-19}$, os quais relatam o predomínio do agravo nas crianças menores de um ano (Tabela 4).

Quanto ao local de moradia dos indivíduos que tiveram 0 caso confirmado, $58 \%$ residiam na zona urbana. Em relação à quantidade de pessoas que residiam no mesmo domicílio onde ocorreram os casos, $70 \%$ eram de 5 ou mais pessoas, e $21 \%$ de 3 a 4 pessoas. Já para 0 número de pessoas que compartilhavam o mesmo quarto com outras pessoas, $52 \%$ dos casos dividiam o cômodo com 1 a 2 pessoas, e $21 \%$ dormiam sozinhos. Com relação ao hábito de compartilhar copos e talheres $42 \%$ dos casos relataram possuir este hábito (Tabela $5)$.

Gráfico 1 - Série histórica dos casos de Meningite na Regional de Saúde de Balsas/MA, período de 2009 a $2012^{4}$

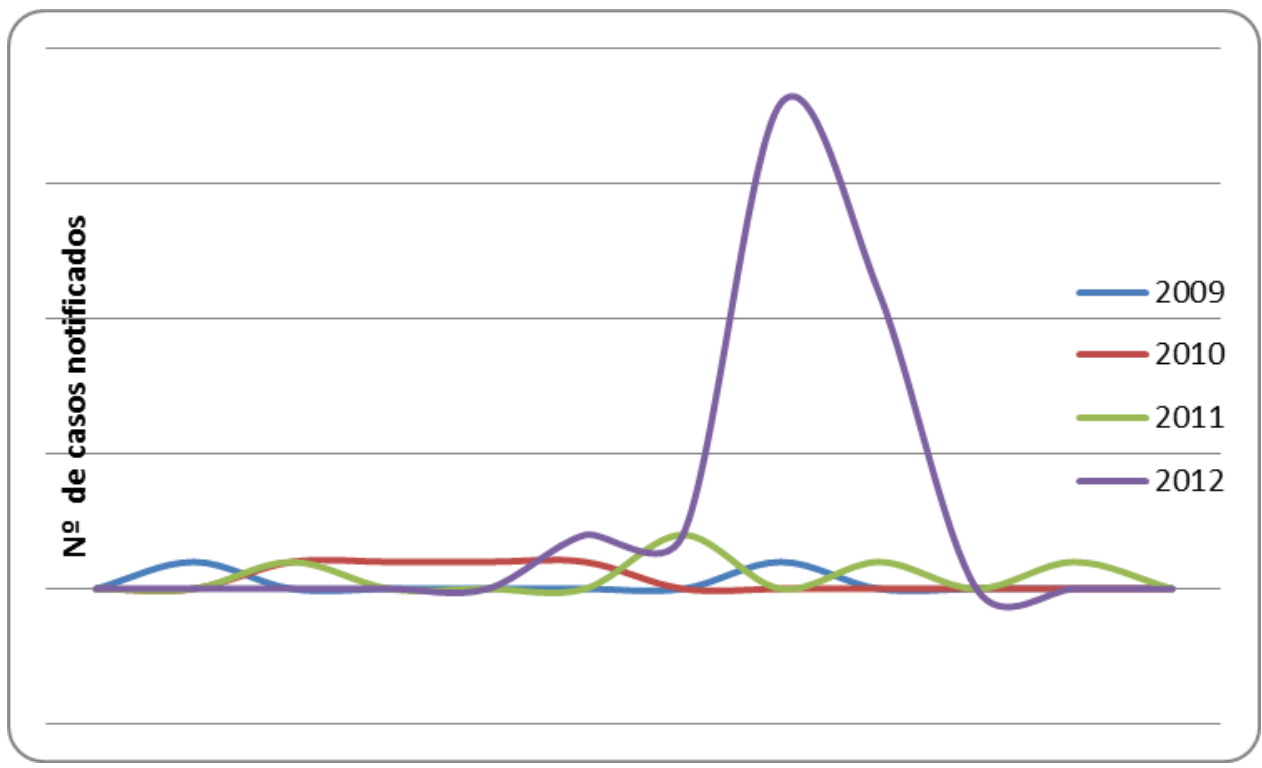

Rev. Investig, Bioméd., São Luís, 7:69-79. 2015 
Tabela 2 - Número de casos confirmados, em investigação, descartados, e óbitos por Doença Meningocócica, segundo município provável de infecção. Regional de Balsas/MA, 2012

\begin{tabular}{lllllll}
\hline \multirow{2}{*}{ Município } & \multicolumn{2}{l}{ Confirmados } & \multicolumn{2}{l}{$\begin{array}{l}\text { Em } \\
\text { investigação }\end{array}$} & \multicolumn{2}{l}{ Descartados } \\
\cline { 2 - 7 } & Caso & Óbito & Caso & Óbito & Caso & Óbito \\
\hline Sambaíba & 15 & 4 & 1 & - & 5 & - \\
Loreto & 4 & 1 & - & - & - & - \\
S. R. Mangabeiras & 3 & 1 & - & - & - & - \\
Balsas & 2 & - & 1 & - & 3 & - \\
Feira Nova & - & - & - & - & 1 & - \\
Riachão & 1 & - & - & - & 1 & - \\
S.F. de Balsas & 1 & - & - & - & 1 & - \\
Fort. Dos Nogueiras & - & 1 & - & - & 1 & - \\
\hline Total & 26 & 7 & 2 & - & 11 & -
\end{tabular}

"Dados fornecidos pela Secretaria de Estado da Saúde do Maranhão, em 2012.

Tabela 3 - Coeficiente de incidência e letalidade de Doença Meningocócica por Município. Regional de Balsas/MA, período de agosto a setembro de $2012^{*}$

\begin{tabular}{lllllll}
\hline Município & Casos & Óbitos & Total & População & Cl & Letalidade $^{* *}$ \\
\hline Balsas & 2 & & 2 & 83528 & 2.4 & 0 \\
Fort. & & 1 & 1 & 11646 & 8.6 & 100 \\
Nogueiras & & 1 & 5 & 11390 & 43.9 & 20 \\
Loreto & 4 & 1 & 4 & 17474 & 22.9 & 25 \\
Mangabeiras & 3 & 1 & 1 & 20209 & 4.9 & 0 \\
Riachão & 1 & & 19 & 5487 & 346.2 & 21 \\
Sambaíba & 15 & 4 & 1 & 4702 & 21.3 & 0 \\
São Félix de & 1 & & 1 & \\
Balsas & 1 & &
\end{tabular}

Dados fornecidos pela Secretaria de Estado da Saúde do Maranhão, em 2012.

"Cálculo realizado por 100.000 Hab. 
Tabela 4 - Número de casos confirmados, em investigação, descartados, e óbitos por Doença Meningocócica, segundo município provável de infecção. Regional de Balsas/MA, $2012^{*}$

\begin{tabular}{lllllll}
\hline \multirow{2}{*}{ Município } & \multicolumn{2}{l}{ Confirmados } & \multicolumn{2}{l}{$\begin{array}{l}\text { Em } \\
\text { investigação }\end{array}$} \\
\cline { 2 - 7 } & Caso & Óbito & Caso & Óbito & Caso & Óbito \\
\hline$<1$ ano & - & - & - & - & 1 & - \\
1 a 2 & - & 1 & - & - & 1 & - \\
3 a 4 & - & - & - & - & 1 & - \\
5 a 9 & 3 & 1 & - & - & - & - \\
10 a 14 & 8 & 1 & - & - & 1 & - \\
15 a 19 & 3 & 1 & 1 & - & 3 & - \\
20 a 29 & 5 & 2 & 1 & - & 3 & - \\
30 a 39 & 3 & 1 & - & - & - & - \\
40 a 49 & 2 & - & - & - & - & - \\
50 a 59 & 1 & - & - & - & 1 & - \\
60 a 69 & 1 & - & - & - & - & - \\
\hline Total & 26 & 7 & 2 & - & 11 & - \\
\hline
\end{tabular}

"Dados fornecidos pela Secretaria de Estado da Saúde do Maranhão, em 2012.

Tabela 5 - Características dos casos de óbitos por Doença Meningocócica. Regional de Saúde de Balsas/MA, período de agosto a setembro de 2012

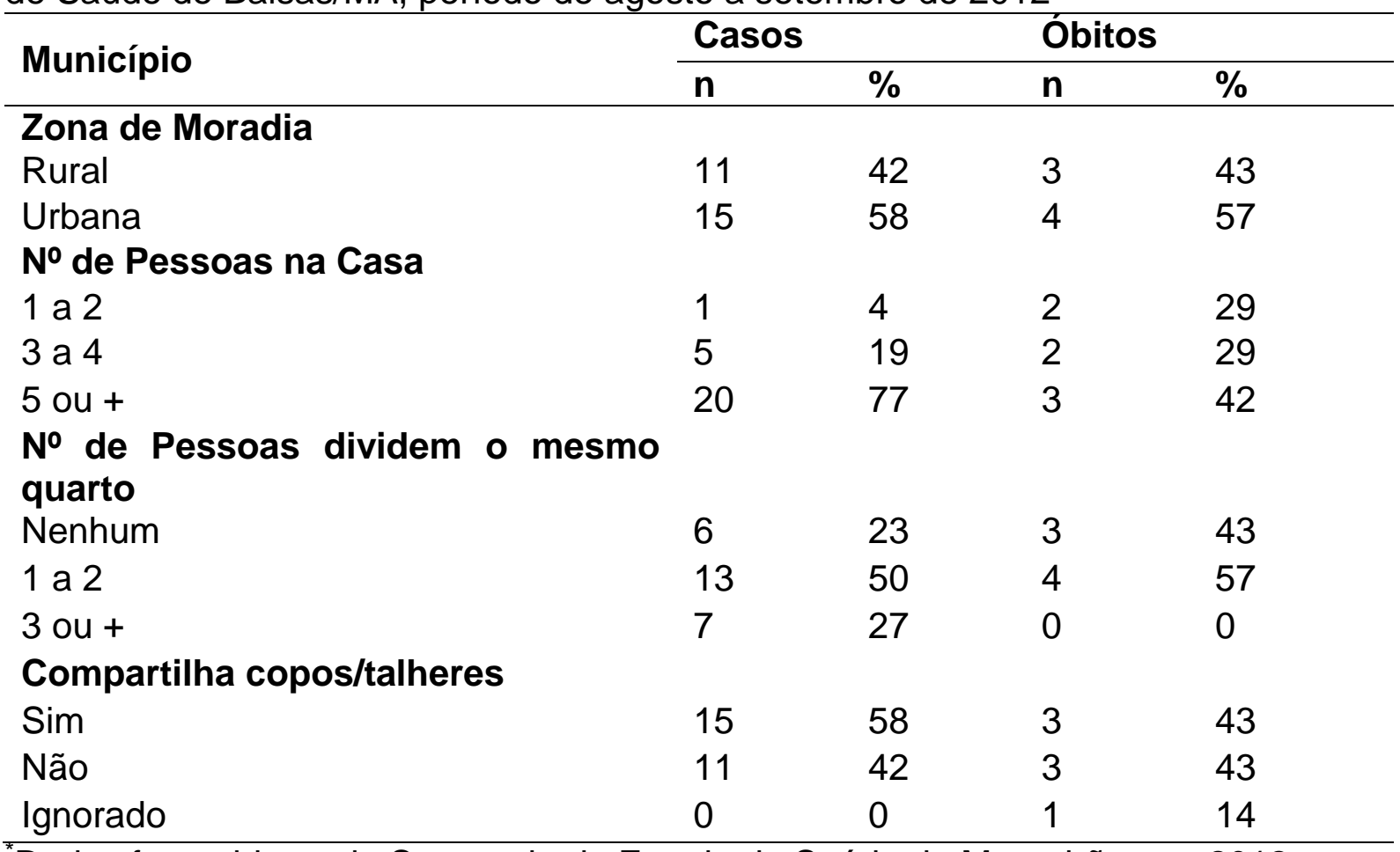

"Dados fornecidos pela Secretaria de Estado da Saúde do Maranhão, em 2012. 
Tabela 6 - Critérios de fechamento de casos de doença meningocócica. Regional de Saúde de Balsas/MA, período de agosto a setembro de $2012^{\star}$

\begin{tabular}{lll}
\hline Critério & Casos & Óbitos \\
\hline Bacterioscopia & 4 & 1 \\
Clínica & 7 & 1 \\
MCC & 2 & 4 \\
Cultura & 2 & - \\
PCR & 10 & 1 \\
Vínculo epidemiológico & 1 & - \\
\hline Total & 26 & 7
\end{tabular}

"Dados fornecidos pela Secretaria de Estado da Saúde do Maranhão, em 2012.

Em análise das atividades desenvolvidas pelos casos confirmados, $48 \%$ estudavam e $35 \%$ desenvolviam alguma atividade laboral. A ocupação com maior frequência foi a de agricultor 58\% (Tabela 5).

As sintomatologias mais frequentes dos casos confirmados foram febre $(100 \%)$, cefaleia $(91 \%)$, vômito $(91 \%)$, rigidez de nuca $(39 \%)$, dor abdominal $(39 \%)$, petéquias $(42 \%)$ e equimose (39\%). Entre os sintomas clássicos da DM, vale ressaltar o registro de cefaleia que ocorreu em
91\% dos casos (gráfico 2). Tal fato discorda com outros estudos ${ }^{20}$, nos quais a cefaleia apresentava-se em menos de $50 \%$ dos casos.

Com relação aos critérios de confirmação dos casos de óbitos para doença meningocócica, $15 \%$ foram confirmados pelo exame laboratorial de bacterioscopia do Liquor cefalorraquidiano, $24 \%$ por clínica, $18 \%$ por meningococcemia (MCC), $6 \%$ por exame laboratorial de cultura do LCR, 34\% por PCR positivo para Neisseria meningitidis, e $3 \%$ por vínculo epidemiológico (Tabela 6).

Gráfico 2 - Situação dos casos confirmados de Doença Meningocócica, segundo os sintomas apresentados. Regional de Saúde de Balsas/MA, período de agosto a setembro de $2012^{*}$

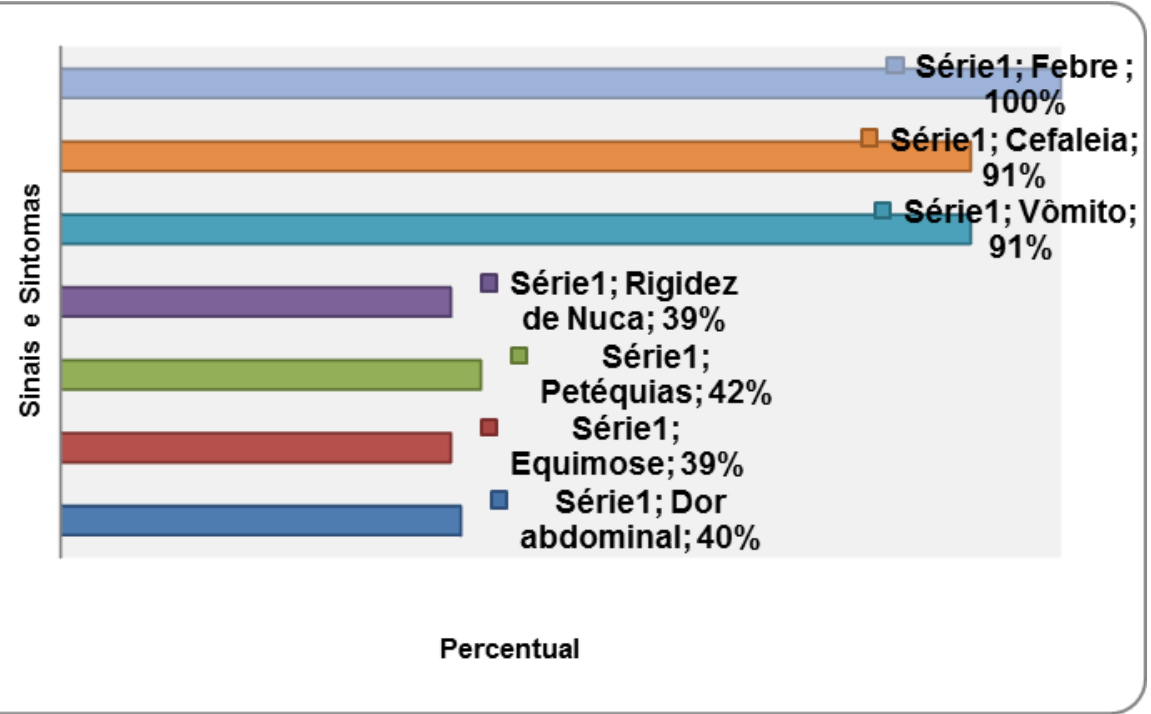

"Dados fornecidos pela Secretaria de Estado da Saúde do Maranhão, em 2012. 


\section{Conclusão}

O presente trabalho indicou que na regional de saúde de Balsas, durante o ano de 2012, o maior número de DM ocorreu em residentes do município de Sambaíba, do sexo masculino com faixa etária maior de 10 anos, com a mediana de idade de 16 anos.

A confirmação dos casos baseada em diagnóstico laboratorial é essencial no controle da doença meningocócica e indica a qualidade do sistema de vigilância epidemiológica. Constatou-se a necessidade de maior especificidade na investigação epidemiológica laboratorial, especialmente quanto à identificação da cepa predominante, pois esse desconhecimento inviabilizou a análise do período referente a essa variável. Este dado é de fundamental importância para o desenvolvimento de vacinas.

Pode-se concluir que o sucesso das ações de vigilância no controle da doença meningocócica está intimamente relacionado a três eixos: a investigação epidemiológica, o manejo clínico do paciente e a investigação laboratorial. $O$ perfeito entrosamento desses eixos é que pode garantir a realização de intervenções eficazes para que seja alcançada a diminuição das taxas de morbidade e de letalidade geradas pelo agravo.

\section{Referências}

1. Harrison LH, Trotter CL, Ramsey ME. Global epidemiology of meningococcal disease. Vaccine. 2009;27 Suppl 2:B51-63.

2. Santos ML, Ruffino-Netto A. Doença meningocócica:situação epidemiológica no Município de Manaus, Amazonas, Brasil, 1998/2002. Cad Saúde Pública. 2005;21(3):823-9.
3. Brasil. Ministério da Saúde. Nota Técnica 53/2011/CDT/DEVIT/SVS/MS.

Dispõe sobre a atualização sobe critérios papa vacinação em caso de surto de doença meningocócica. Brasília: Ministério da Saúde; 2011.

4. Brasil. Sistema de Informação de Agravos de Notificação. Meningite: casos confirmados notificados no Sistema de Informação de Agravos de Notificação - Sinan Net [internet]. Brasília: Ministério da Saúde; 2014 [acesso 2014 maio 8]. Disponível em: http://dtr2004.saude.gov.br/sinanwe $\mathrm{b} / \mathrm{tabnet} / \mathrm{dh}$ ?sinannet/meningite/bas es/meninbrnet.def.

5. Sáfadi MAP, Berezin EN, Oselka GW. Análise crítica das recomendações do uso das vacinas conjugadas. meningocócicas 2012;88(3):195-202.

6. Brasil. Ministério da Saúde. Secretaria de Vigilância em Saúde. Departamento de Vigilância Epidemiológica. Guia de vigilância epidemiológica. $7^{\text {a }}$ ed. Brasília: Ministério da Saúde; 2010.

7. Granoff DM, Harrison LH, Borrow R. Meningococcal vaccines. In: Plotkin SA, Orenstein WA, Offit PA, Editores. Vaccines. $5^{\mathrm{a}}$ ed. Philadelphia: Saunders/Elsevier; 2008. p. 399-434.

8. Brasil. Ministério da Saúde. Secretaria de Vigilância em Saúde. Guia de vigilância epidemiológica [Internet]. Brasília: Ministério da Saúde; 2005 [acesso 2015 set 16]. Disponível em: http://bvsms.saude.gov.br/bvs/publ icacoes/Guia_Vig_Epid_novo2.pdf.

9. World Health Organization. Emergencies preparedness, response [Internet]. Geneva: 
WHO; 2014 [acesso 2015 maio 10]. Disponível em: http://www.who.int/csr/disease/me ningococcal/en/.

10. Laguardia J, Domingues CMA, Carvalho C, Lauerman CR, Macário E, Glatt R. Sistema de Informação de Agravos de Notificação (SINAN): desafios não desenvolvimento de um sistema de informação em saúde. Epidemiol Serv Saúde. 2004;13(3):135-47.

11. Brasil. Ministério da Saúde. Secretaria de Vigilância em Saúde. Departamento de Vigilância Epidemiológica. Guia de vigilância epidemiológica [Internet]. Brasília: Ministério da Saúde; 2009 [acesso em 2014 abr 15]. Disponível em: http://bvsms.saude.gov.br/bvs/ publicacoes/guia_vigilancia_epide miologica_7ed.pdf.

12. Instituto Brasileiro De Geografia $E$ Estatística. Cudades@: Maranhão [Internet]. [acesso 2014 maio 8]. Disponível em: http://www.cidades.ibge.gov.br/xtra s/uf.php?lang=\&coduf $=21 \&$ search $=$ maranhao.

13. Gama SGN, Marzochi KB, Silveira GB. Caracterização epidemiológica da doença meningocócica na área metropolitana do Rio de Janeiro, Brasil, 1976 a 1994. Rev Saúde Pública. 1997;31(3):254-62.

14. Bryan JP, Silva HR, Tavares Um, Rocha H, Scheld WM. Etiology and mortality of bacterial meningitides in Northeastern Brazil. Rev Infect Dis. 1990; 12 (1):128-35.

15. Fogarty J, Keane CT, Carroll R, Byrne $\mathrm{H}$, Moloney AC. Meningococcal disease in childhood a regional study in Ireland. J Infect 1994;28(2):199207.

16. Dure-Samin A, Mubina A, Azra Y. An Epidemic of Meningococcal Disease in Karachi (Pakistan): a study of Children. Acta Paediatr Jpn. 1991;33(3):352-6.

17. Greenwood B. Meningococcal disease. In: Strickland TG. Hunter's tropical medicine. $7^{a}$ ed. Filadélfia: Saunder's Co; 1991. p. 385-92.

18. Jafari SH, McCracken HG. Sepsis and septic shock: a review for clinicians. Crit Cuidados 2012;16 (1):204.

19. Granier SP, Owen RP, Jacobson L. Recognizing meningococcal disease in primary care: qualitative study of how general practitioners process clinical and contextual information. BMJ 1998;316(7127):276-9.

20. Martinez-de La Iglesia J, Montero Perez FJ, Fernández Crehvet NR. Enfermidad meningocócica en la provincia de Córdoba (1983-1987). Enfermidades infecciosas y Microbiologia Clínica. 1990;8:4205. 